\title{
BMJ Open Statin adherence and risk of acute cardiovascular events among women: a cohort study accounting for time- dependent confounding affected by previous adherence
}

\author{
Piia Lavikainen, ${ }^{1,2}$ Arja Helin-Salmivaara, ${ }^{1,3}$ Mervi Eerola, ${ }^{4}$ Gang Fang, ${ }^{5}$ \\ Juha Hartikainen, ${ }^{6,7}$ Risto Huupponen, ${ }^{1,8}$ Maarit Jaana Korhonen ${ }^{1,5}$
}

To cite: Lavikainen $P$, HelinSalmivaara A, Eerola M, et al. Statin adherence and risk of acute cardiovascular events among women: a cohort study accounting for timedependent confounding affected by previous adherence. BMJ Open 2016;6:e011306.

doi:10.1136/bmjopen-2016011306

- Prepublication history and additional material is available. To view please visit the journal (http://dx.doi.org/ 10.1136/bmjopen-2016011306).

Received 27 January 2016 Revised 19 April 2016 Accepted 22 April 2016

CrossMark

For numbered affiliations see end of article.

Correspondence to

Piia Lavikainen;

piia.lavikainen@utu.fi

\section{ABSTRACT}

Objectives: Previous studies on the effect of statin adherence on cardiovascular events in the primary prevention of cardiovascular disease have adjusted for time-dependent confounding, but potentially introduced bias into their estimates as adherence and confounders were measured simultaneously. We aimed to evaluate the effect when accounting for timedependent confounding affected by previous adherence as well as time sequence between factors.

Design: Retrospective cohort study.

Setting: Finnish healthcare registers.

Participants: Women aged 45-64 years initiating statin use for primary prevention of cardiovascular disease in 2001-2004 ( $n=42$ 807).

Outcomes: Acute cardiovascular event defined as a composite of acute coronary syndrome and acute ischaemic stroke was our primary outcome. Lowenergy fractures were used as a negative control outcome to evaluate the healthy-adherer effect.

Results: During the 3-year follow-up, 474 women experienced the primary outcome event and 557 suffered a low-energy fracture. The causal HR estimated with marginal structural model for acute cardiovascular events for all the women who remained adherent (proportion of days covered $\geq 80 \%$ ) to statin therapy during the previous adherence assessment year was 0.78 (95\% Cl: 0.65 to 0.94 ) when compared with everybody remaining non-adherent ( proportion of days covered $<80 \%$ ). The result was robust against alternative model specifications. Statin adherers had a potentially reduced risk of experiencing low-energy fractures compared with non-adherers (HR 0.90, 95\% Cl 0.76 to 1.07 ).

Conclusions: Our study, which took into account the time dependence of adherence and confounders, as well as temporal order between these factors, is support for the concept that adherence to statins in women in primary prevention decreases the risk of acute cardiovascular events by about one-fifth in comparison to non-adherence. However, part of the observed effect of statin adherence on acute cardiovascular events may be due to the healthy-adherer effect.

\section{Strengths and limitations of this study}

- Large population-based register study covering all female statin initiators in primary prevention of cardiovascular disease in 2001-2004.

- This study expanded on previous studies by allowing for time dependence of adherence and confounders as well as accounting for timedependent confounders which could have been affected by previous adherence.

- Sensitivity analyses to account for a potential selection bias as well as healthy-adherer effect were conducted.

- Data on some important confounders, such as cholesterol level and smoking, were not available to us.

\section{INTRODUCTION}

Several population-based studies have investigated associations between adherence to statin therapy, defined typically as proportion of days covered ${ }^{1}$ (PDC) or medication possession ratio $^{1}$ (MPR) $\geq 80 \%$, and cardiovascular morbidity in primary prevention of cardiovascular disease (CVD).$^{2-8}$ Uniformly, these studies have reported reductions in the risk of cardiovascular events in association with adherence when compared with nonadherence. Previous studies have also shown that patients' adherence to statin therapy varies over time, ${ }^{7} 9$ and transitions to lower adherence levels may be associated with an increased risk of cardiovascular events. ${ }^{7}$ Our recent study examined adherence with two different approaches: first as a fixed variable measured during the first year since initiation and second as a time-dependent variable measured at 1-year intervals since therapy initiation; comparable reductions in the risk of various cardiovascular events were observed with both approaches. ${ }^{8}$ 
Most prior studies have used $\operatorname{cohort}^{5-8}$ and nested case-control designs ${ }^{2-4}$ to assess the effect of adherence on cardiovascular morbidity. Typically, adherence has been measured as a single, fixed average throughout the follow-up. ${ }^{2-6}$ As follow-up periods have varied from 3 to 12 years at maximum, very different adherence patterns may have led to the same values of PDC or MPR. ${ }^{2-6}$ Confounders have been assessed at baseline and some also time-dependently during the follow-up, that is, during the same period as adherence. ${ }^{2-6}$ Consequently, the values of these confounders (eg, switching to a more potent statin in this case) may have been affected by prior adherence. Conditioning on intermediate variables that lie on the causal pathway between adherence and outcome blocks some of the adherence effect, and may introduce a collider-stratification bias if there are unmeasured confounders that predict both the intermediate variable and the outcome. ${ }^{10}{ }^{11}$ In addition, one major concern in observational studies is healthy-adherer bias emerging from differences in unmeasured health-seeking behaviours between the groups to be compared. ${ }^{12-14}$ Employment of negative control outcomes that reflect unhealthy behaviours unrelated to medication effect is one way to evaluate the role of such bias in the study results. ${ }^{15}$

Inverse probability of treatment weighted estimation of marginal structural models (MSMs) can be employed to overcome the problems caused by time-dependent confounding affected by prior exposure in observational studies. ${ }^{10} 16^{17}$ This study employed the MSM approach to extend previous studies by now accounting for timedependent confounding affected by prior adherence when estimating the effect of statin adherence on the incidence of acute cardiovascular events. We compared the results with those obtained with conventional models. We accounted for the time-varying nature of adherence by measuring it in yearly periods, and adjusted for several time-dependent confounders. In addition, we used low-energy fractures as the negative control outcome to examine the impact of unmeasured confounding on the effect estimates.

\section{METHODS}

The data originated from multiple administrative healthcare registers. The Finnish Prescription Register maintained by the Social Insurance Institution (SII) catalogues information on reimbursed medications, such as dispensing date, Anatomical Therapeutic Chemical (ATC) classification code, ${ }^{18}$ strength and the quantity dispensed, for all Finnish residents. The Special Reimbursement Register, also maintained by the SII, contains information on entitlements to higher medication reimbursement due to specific chronic diseases such as diabetes and coronary heart disease (CHD). Patients staying at public nursing homes or hospitalised for over 90 consecutive days are not eligible for reimbursement, and their purchases are not registered.
These long-term institutionalised patients can be identified from a separate SII register. The Finnish Care Register maintained by the National Institute for Health and Welfare covers all Finnish hospitals and includes information on primary and secondary discharge diagnoses, surgical procedures and admission and discharge dates. The 10th revision of the International Classification of Diseases (ICD-10) was in use during the study period. Statistics Finland compiles information from many sources such as the Register of Completed Education and Degrees, the Population Information System of the Population Register Centre, and the Finnish Tax Administration. All register data were linked using personal identification numbers unique to every Finnish resident.

\section{Ethics, consent and permissions}

Permissions were obtained from the register holders (the SII, the National Institute for Health and Welfare, and the Statistics Finland). Ethical approval was not needed as we did not contact the patients and used de-identified data. No written consent was required nor sought.

\section{Study population}

A cohort of women initiating statins (ATC codes: C10AA01-C10AA07) in 2001-2004 and aged 45-64 years was created from the Prescription Register. A new user was defined as an individual who had not been dispensed with statins in the time period after 1994, when the register was established. The date of the first statin purchase was defined as the cohort entry date. Patients who were long-term institutionalised within 3 years prior to or at statin initiation were excluded as were those whose first purchase was cerivastatin (C10AA06), a medication withdrawn from the market in 2001.

Furthermore, in order to identify those women who initiated statin therapy for primary prevention of CVD, we excluded all patients for whom there was evidence of atherosclerotic CVD in the registers. More specifically, we excluded patients who were hospitalised due to CHD (ICD-10 codes: I20-I25 as a primary or secondary diagnosis), cerebrovascular diseases or transient ischaemic attack (I60-I66, I68-I69, G45-G46), atherosclerosis (I70), aneurysm (I71) or any medical procedure related to CHD (coronary artery bypass graft $(\mathrm{CABG})$, or percutaneous transluminal coronary angioplasty (PTCA)), cerebrovascular diseases (carotid endarterectomy or thrombolytic therapy), or peripheral artery disease and/or purchased nitrates (ATC class: C01DA) during the 3 years prior to statin initiation; and/or who were entitled to higher medication reimbursement due to chronic CHD at statin initiation (see online supplementary table S1). We excluded also patients who had purchased lipid modifying medications other than statins within 3 years prior to statin initiation. Patients who died or were institutionalised or had an outcome event within the first year after statin initiation were excluded. The flow chart of the cohort composition is presented in figure 1 . 


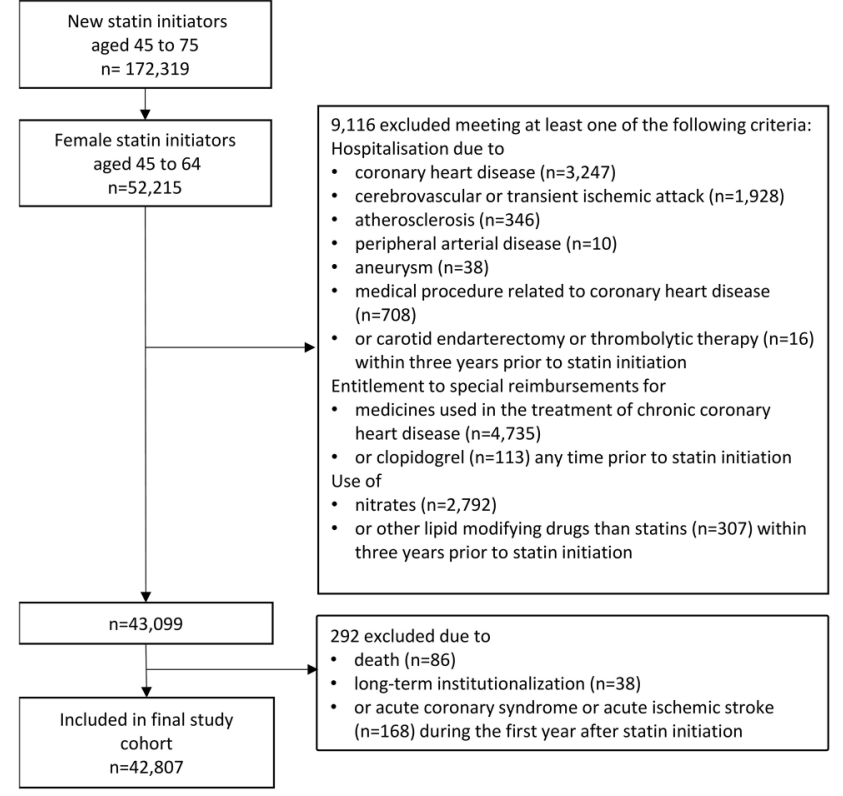

Figure 1 Flow chart of the cohort of women initiating statins for primary prevention of cardiovascular disease.

The outcome follow-up started 1 year after the statin initiation (figure 2) because computation of adherence for time periods shorter than 1 year may be unstable, ${ }^{19}$ and to exclude early outcomes that occurred before the therapeutic response to statin therapy could be established. ${ }^{20-24}$ The follow-up lasted up to 3 years (from 12 to 48 months after statin initiation). We followed patients until they experienced the outcome of interest, died, were long-term institutionalised (adherence cannot be defined during the long-term care) or 48 months was reached, whichever occurred first.

\section{Adherence to statin therapy}

Statin adherence was measured from the Finnish Prescription Register as $\mathrm{PDC}^{1925}$ at 1-year intervals since statin initiation (figure 2). Using a validated dosage assumption of one tablet per day, ${ }^{26}$ we calculated the number of days covered by dispensed statin tablets during each 1-year period and divided it by 365 . When a refill overlapped with the previous dispensing, the new dispensing was assumed to start the day after the end of the prior dispensing. Switching between statins was considered as a continuation of therapy. Denominators were corrected for days in hospital because medications during hospitalisation are provided by the service provider. Finally, women were classified as adherent or nonadherent by applying the conventional cut-off value of PDC $\geq 80 \%$. $^{2728}$

\section{Outcomes}

The outcome was a composite of an acute cardiovascular event defined as a hospitalisation for an acute coronary syndrome (ACS) (ICD-10 codes: I20.0, I21-I22) or an acute ischaemic stroke (I63) as a primary diagnosis in the Finnish Care Register (see online supplementary table S2).

\section{Confounders}

In the construction of inverse probability of treatment weights (IPTWs), adherence models should include common causes of adherence and outcome (confounders), and pure risk factors. ${ }^{29} 30$ After reviewing the literature $^{23}$ and receiving expert opinions about associations with the outcome, we identified several potential confounders. Directed acyclic graphs were used to describe the relationships between adherence, outcome events and confounders (figure 3) when making decisions about the need for adjustments in the statistical analyses.

Baseline confounders measured prior to or at statin initiation included sociodemographic and socioeconomic factors, type and intensity of the initial statin therapy (modified from Stone $e t a l^{11}$ ), year of statin initiation, cardiac comorbidity factors (such as diabetes, hypertensive diseases, heart failure/chronic cardiac insufficiency, cardiac arrhythmias, dysfunctions of lipid metabolism, number of cardiovascular medications in use and Charlson Comorbidity Index ${ }^{32}$ ) and non-cardiac comorbidity factors (such as rheumatoid arthritis and depression). Detailed definitions and classifications of baseline confounders are presented in online supplementary table S3.

After statin initiation, we measured cardiac and noncardiac confounders as well as marital status, income, labour market status and any increase in the intensity of statin therapy on an annual basis. In addition, we treated chronic forms of atherosclerotic CVD, such as chronic CHD, CABG/PTCA, chronic cerebrovascular disease or transient ischaemic attack, atherosclerosis and use of nitrates, appearing after statin initiation as timedependent confounders. Detailed definitions and classifications of time-dependent confounders are presented in online supplementary table S4.

\section{Statistical modelling}

We compared the results from conventional discretetime hazards models with those estimated from MSMs. Both models were estimated with a pooled log-binomial regression model to produce a collapsible effect measure $^{33}$ for the comparison purpose (conditional vs marginal effect estimate). Outcome was assessed at monthly intervals so that each person-month was treated as an observation. First, we examined a discrete-time hazards model with time dependent dichotomous adherence to produce a crude HR (model 1) for the effect of statin adherence on acute cardiovascular events. Next, we adjusted the crude effect estimate for baseline confounders (model 2). Finally, we used MSMs to adjust for time-dependent confounding affected by prior adherence. ${ }^{17}$ In MSMs, the study population is weighted to produce a pseudo-population in which confounders are balanced between the adherence groups, 


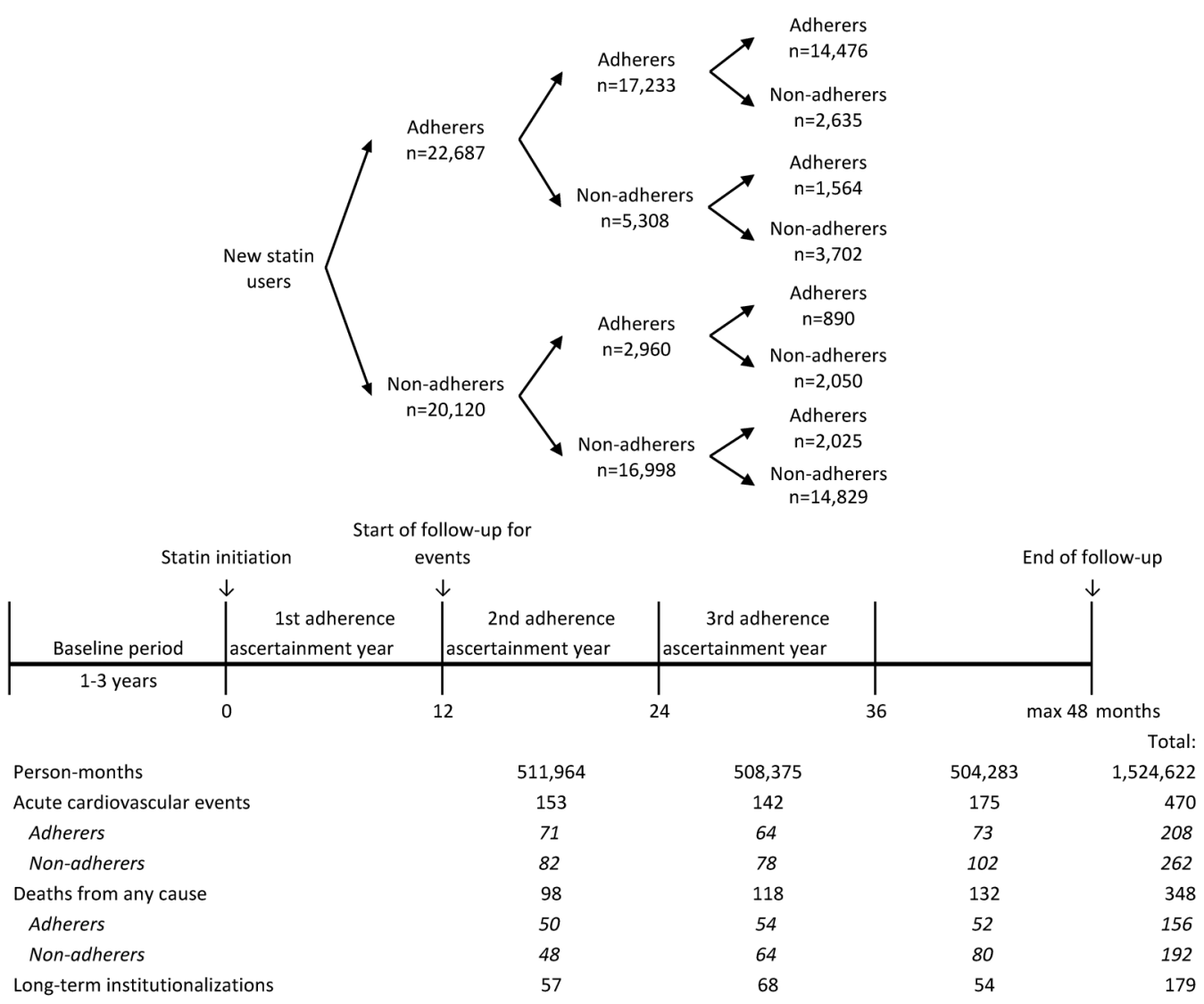

Figure 2 Schematic study design.

but the causal effect of the adherence on the outcome is preserved. ${ }^{17}$

We derived year-specific IPTWs for MSMs by applying logistic regression models as adherence models to estimate each individual's probability of having the observed adherence at three time points; at 12, 24 and 36 months since statin initiation (figure 2). At 12 months after statin initiation, we calculated IPTW as an inverse probability of the observed first-year adherence conditional on baseline confounders. The IPTW was stabilised with the prevalence of observed first-year adherence to increase the precision of the MSM estimator (see online supplementary appendix 1). At 24 and 36 months after statin initiation, the inverse probability of adherence

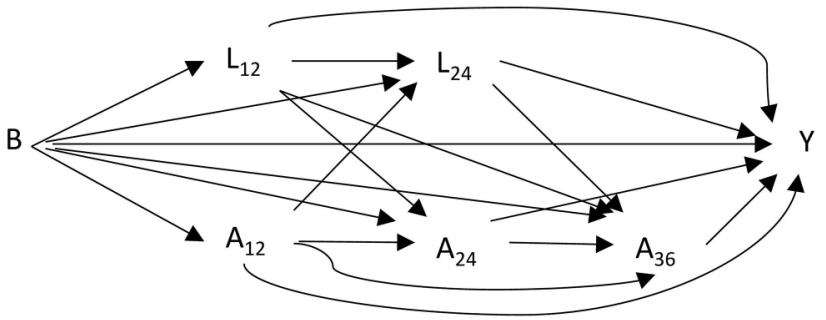

Figure 3 Directed acyclic graph for time-dependent adherence and confounding structure. $B$, baseline characteristics; $A_{12}-A_{36}$, time-dependent adherences measured at months 12,24 and $36 ; L_{12}-L_{24}$, time-dependent confounders measured at months 12 and 24 ; $Y$, outcome. observed over the previous year was calculated conditional on adherence history, baseline confounders, and lagged time-dependent confounders that were measured prior to that adherence assessment period (figure 3) to ensure conditioning only on prior values of confounders. ${ }^{34}$ At 24 and 36 months after statin initiation the probabilities of observed adherences conditional on adherence histories were used to stabilise the inverse probabilities. The stabilised IPTWs at 24 and 36 months after statin initiation were calculated cumulatively by multiplying the stabilised inverse probabilities from previous time points up to the specific time point. The balancing properties of the stabilised IPTWs were checked by using standardised difference (SD) to compare confounder distributions between the two adherence groups in each of the yearly periods. An SD value $>0.1$ was considered as an indication of a meaningful difference between the groups. ${ }^{35}$

MSMs were estimated using pooled log-binomial regression models weighted with stabilised IPTWs for person-month data (see online supplementary appendix 1). We examined the average causal effect of adherence (PDC $\geq 80 \%$ ) versus non-adherence (PDC $<80 \%$ ) during the previous adherence ascertainment year on the hazard of acute cardiovascular events using MSM (model 3 ). To test the robustness of our results against extreme weights, we examined the effect of truncating ${ }^{32}$ the stabilised IPTWs at the 1st and 99th centiles (model 4). 
We performed several sensitivity analyses. First, we used time-dependent confounders measured simultaneously with adherence in adherence models to demonstrate the impact of the miss-specified time sequence on the effect estimate (see online supplementary appendix 2 and figure S1 for more information on sensitivity analyses). Second, we added medical procedures (CABG/ PTCA) and death from any cause into the composite outcome to evaluate the effect of potential selection bias as these events may be viewed as competing risks. ${ }^{36}$ Third, we compared patients who had at least once refilled their statin prescription (at least slight adherence) to those with no refills after the first dispensation (extreme non-adherence) (see online supplementary appendix 2 and figure S2). We assumed that patients with only the initial dispensation during the follow-up would mimic those with the same indication but no statin exposure, that is, a placebo group in randomised controlled trials.

Finally, we wanted to evaluate the healthy-adherer effect as an alternative explanation for our observations (models 5 and 6). ${ }^{15}$ For that, we used low-energy fractures as a negative control outcome that could reflect unhealthy behaviours, but is unrelated to statin effect. ${ }^{37}$ Fractures were identified as the first hospital visit for a low-energy fracture of hip (ICD-10 codes S32.1-S32.4, S72.0-S72.8 as a primary or secondary diagnosis), wrist (S52.0, S62.4), ankle (S82.1-S82.7, S92.0, S92.3), or forearm (S42.2-S42.4) (see online supplementary table S2). We used the same adherence models as in models 3 and 4 to derive IPTWs for MSM.

The analyses were performed using SAS software V.9.4 (SAS Institute Inc, Cary, North Carolina, USA), see SAS syntax for the primary analysis in online supplementary appendix 1 . Missing values in variables measured after statin initiation $(120.03 \%$ patients missed data on both marital status and labour market status) were imputed with the last observation carried forward technique.

\section{RESULTS}

We identified 52215 women aged 45-64 years who initiated statin therapy during 2001-2004. After exclusions, our final cohort consisted of 42807 women (figure 1). The mean age was 56.2 years (SD: 4.9) and $53.0 \%$ were adherent to statin therapy (PDC $\geq 80 \%$ ) during the first year after initiation (table 1). Baseline confounders were well balanced between the adherent and non-adherent women (table 1 and online supplementary table S5). The mean PDC was $94.0 \%$ among adherers, and $43.7 \%$ among non-adherers during the first assessment year. Of those who were adherent during the first year, $76.0 \%$ remained adherent in the second year, and $63.8 \%$ remained in this state for 3 years. Of the non-adherers during the first year, $84.5 \%$ remained non-adherent for 2 years and $73.7 \%$ for 3 years after statin initiation (figure 2). At baseline, agents acting on the renin-angiotensin system were being used by $26.4 \%$

\begin{tabular}{|c|c|c|c|c|c|}
\hline & \multicolumn{2}{|c|}{$\begin{array}{l}\text { Non-adherers } \\
\text { (PDC <80\%) } \\
(n=20120)\end{array}$} & \multicolumn{2}{|c|}{$\begin{array}{l}\text { Adherers } \\
\text { (PDC } \geq 80 \%) \\
(n=22687)\end{array}$} & \multirow[b]{2}{*}{ SD } \\
\hline & $\mathbf{n}$ & $\begin{array}{l}\text { Per } \\
\text { cent }\end{array}$ & $\mathbf{n}$ & $\begin{array}{l}\text { Per } \\
\text { cent }\end{array}$ & \\
\hline \multicolumn{6}{|l|}{ Age, years } \\
\hline $45-49$ & 2423 & 12.0 & 2238 & 9.9 & 0.070 \\
\hline $50-54$ & 5286 & 26.3 & 5409 & 23.8 & 0.056 \\
\hline $55-59$ & 6621 & 32.9 & 7949 & 35.0 & 0.045 \\
\hline $60-64$ & 5790 & 28.8 & 7091 & 31.3 & 0.054 \\
\hline \multicolumn{6}{|c|}{ Statin at baseline } \\
\hline Simvastatin & 7801 & 38.8 & 8768 & 38.7 & 0.003 \\
\hline Lovastatin & 373 & 1.9 & 337 & 1.5 & 0.029 \\
\hline Pravastatin & 1421 & 7.1 & 1046 & 4.6 & 0.105 \\
\hline Fluvastatin & 1485 & 7.4 & 1818 & 8.0 & 0.024 \\
\hline Atorvastatin & 7147 & 35.5 & 8095 & 35.7 & 0.003 \\
\hline Rosuvastatin & 1893 & 9.4 & 2623 & 11.6 & 0.070 \\
\hline \multicolumn{6}{|c|}{ Intensity of statin therapy } \\
\hline Low* & 5954 & 29.6 & 7114 & 31.4 & 0.038 \\
\hline Moderate $\dagger$ & 14057 & 69.9 & 15512 & 68.4 & 0.032 \\
\hline High $\ddagger$ & 109 & 0.5 & 61 & 0.3 & 0.043 \\
\hline Diabetes & 2040 & 10.1 & 2732 & 12.0 & 0.061 \\
\hline Insulin & 605 & 3.0 & 765 & 3.4 & 0.021 \\
\hline $\begin{array}{l}\text { Hypertensive } \\
\text { diseases }\end{array}$ & 5246 & 26.1 & 6485 & 28.6 & 0.056 \\
\hline \multicolumn{6}{|c|}{ Number of concurrent CVD medications } \\
\hline 0 & 10443 & 51.9 & 10812 & 47.7 & 0.085 \\
\hline 1 & 5470 & 27.2 & 6682 & 29.5 & 0.050 \\
\hline 2 & 3078 & 15.3 & 3781 & 16.7 & 0.037 \\
\hline $3-6$ & 1129 & 5.6 & 1412 & 6.2 & 0.026 \\
\hline Depression & 2624 & 13.0 & 3089 & 13.6 & 0.017 \\
\hline $\begin{array}{l}\text { Respiratory } \\
\text { diseases }\end{array}$ & 3418 & 17.0 & 3502 & 15.4 & 0.042 \\
\hline $\begin{array}{l}\text { Hormone } \\
\text { therapy }\end{array}$ & 7654 & 38.0 & 9398 & 41.4 & 0.069 \\
\hline \multicolumn{6}{|c|}{ Total number of concurrent medications } \\
\hline $1-2$ & 7085 & 35.2 & 7289 & 32.1 & 0.065 \\
\hline $3-5$ & 7202 & 35.8 & 8037 & 35.4 & 0.001 \\
\hline $6-31$ & 5833 & 29.0 & 7361 & 32.5 & 0.077 \\
\hline \multicolumn{6}{|c|}{ Number of in-hospital days } \\
\hline 0 & 12193 & 60.6 & 14222 & 62.7 & 0.043 \\
\hline $1-2$ & 3902 & 19.4 & 4099 & 18.1 & 0.034 \\
\hline $3-7$ & 2656 & 13.2 & 2825 & 12.5 & 0.022 \\
\hline 8-321 & 1369 & 6.8 & 1541 & 6.8 & 0.000 \\
\hline \multicolumn{6}{|c|}{ Charlson Comorbidity Index } \\
\hline$\geq 1$ & 1307 & 6.5 & 1583 & 7.0 & 0.019 \\
\hline
\end{tabular}

*Fluvastatin 20-40 mg, lovastatin $20 \mathrm{mg}$, pravastatin $10-20 \mathrm{mg}$, simvastatin $5-10 \mathrm{mg}$.

†Atorvastatin 10-20 mg, fluvastatin $80 \mathrm{mg}$, lovastatin $40 \mathrm{mg}$, pravastatin $40 \mathrm{mg}$, rosuvastatin $10 \mathrm{mg}$, simvastatin $20-40 \mathrm{mg}$. ¥Atorvastatin $40-80 \mathrm{mg}$, rosuvastatin $20-40 \mathrm{mg}$, simvastatin $80 \mathrm{mg}$.

CVD, cardiovascular disease; PDC, proportion of days covered;

$\mathrm{SD}$, standardised difference.

of the women, $\beta$ blocking agents by $25.8 \%$, diuretics by $13.0 \%$, calcium channel blockers by $11.2 \%$ and antithrombotic agents by $1.8 \%$.

During the follow-up, 470 women experienced an acute cardiovascular event (ACS, n=256, or acute 
Table 2 Effect of statin adherence on the hazard of an acute cardiovascular event

\begin{tabular}{|c|c|c|c|c|c|}
\hline \multirow[b]{2}{*}{ Model } & \multirow[b]{2}{*}{ Type of model } & \multirow[b]{2}{*}{ Variables in adherence model } & \multirow[b]{2}{*}{ Variables in outcome model } & \multicolumn{2}{|c|}{$\begin{array}{l}\text { Adherents vs } \\
\text { non-adherents }\end{array}$} \\
\hline & & & & HR & $95 \% \mathrm{Cl}$ \\
\hline 1 & $\begin{array}{l}\text { Discrete-time hazards } \\
\text { model }\end{array}$ & Not applicable & Time-dependent adherence & 0.82 & 0.68 to 0.98 \\
\hline 2 & $\begin{array}{l}\text { Discrete-time hazards } \\
\text { model }\end{array}$ & Not applicable & $\begin{array}{l}\text { Time-dependent adherence } \\
\text { and baseline confounders* }\end{array}$ & 0.76 & 0.63 to 0.91 \\
\hline 3 & MSM & $\begin{array}{l}\text { Adherence history, baseline* and } \\
\text { lagged time-dependent } † \\
\text { confounders }\end{array}$ & $\begin{array}{l}\text { Adherence during the } \\
\text { previous assessment year }\end{array}$ & 0.78 & 0.65 to 0.94 \\
\hline 4 & $\begin{array}{l}\text { MSM, weights truncated } \\
\text { at } 1 \text { st and 99th centiles }\end{array}$ & $\begin{array}{l}\text { Adherence history, baseline* and } \\
\text { lagged time-dependent } † \\
\text { confounders }\end{array}$ & $\begin{array}{l}\text { Adherence during the } \\
\text { previous assessment year }\end{array}$ & 0.78 & 0.65 to 0.94 \\
\hline
\end{tabular}

ischaemic stroke, $n=214$ ) (figure 2). The study population produced 753796 adherent person-months and 770826 non-adherent person-months with 208 and 262 acute cardiovascular events. Discrete-time hazards model with time-dependent adherence and time as predictors resulted in a crude HR of 0.82 (95\% CI 0.68 to 0.98 ) for the effect of adherence on acute cardiovascular events (model 1, table 2). When the model was adjusted for baseline confounders, HR decreased to 0.76 (95\% CI 0.63 to 0.91 ) (model 2 , table 2 ).

The estimated HR of the MSM was 0.78 (95\% CI 0.65 to 0.94$)$; thus, an average of $22 \%$ reduction in the hazard of acute cardiovascular events had all the women remained adherent during the previous adherence ascertainment year when compared with if all of them had stayed non-adherent (model 3, table 2). According to SD values, the ability of the stabilised IPTWs to balance the baseline and time-dependent confounders between adherers and non-adherers was good (see online supplementary table S6). The means of the stabilised IPTWs were equal to 1 (table 3 ). In order to eliminate the effect of observations with extreme weights, we truncated the stabilised IPTWs at the 1st and 99th centiles (range of the truncated stabilised IPTWs: 0.66, 1.59); this did not alter the estimation results (model 4 , table 2 ).
In the sensitivity analyses, replacing time-dependent confounders that were measured prior to the adherence assessment period with the values measured concurrently with adherence in the adherence models reduced the HR estimate to $0.74(95 \%$ CI 0.61 to 0.89$)$ (see online supplementary appendix 2 and table $\mathrm{S} 7$ ). Addition of CABG/PTCA and death from any cause to the composite outcome resulted in a HR 0.79 (95\% CI 0.69 to 0.90 ) when estimated with the MSM (see online supplementary appendix 2 and table S7). Those women who were at least slightly adherent (refilled once or more) had a potentially reduced risk of acute cardiovascular events (HR: $0.85,95 \%$ CI 0.62 to 1.16 ) when compared with extremely non-adherent patients (no refills) when estimated with MSMs (see online supplementary appendix 2 and table S8).

Lastly, the causal effect of adherence to statins on lowenergy fractures was explored. Among 42301 women without low-energy fractures within 3 years prior to statin initiation as well as during the first adherence ascertainment year, 557 suffered a low-energy fracture during the 3-year follow-up. Statin adherers had a potentially reduced risk of experiencing fractures compared with non-adherers when estimated with the MSM (HR: 0.90 , $95 \%$ CI 0.76 to 1.07 ).

Table 3 Year-specific distributions of stabilised inverse probability of treatment weights

\begin{tabular}{lllllll}
\hline Time since statin initiation (months) & Mean & Median & Minimum & Maximum & 1st centile & 99th centile \\
\hline 12 & 1.00 & 0.98 & 0.57 & 3.02 & 0.72 & 1.47 \\
24 & 1.00 & 0.97 & 0.17 & 10.47 & 0.68 & 1.57 \\
36 & 1.00 & 0.97 & 0.15 & 11.24 & 0.62 & 1.67 \\
\hline
\end{tabular}




\section{DISCUSSION}

When applying MSM methodology, we detected a $22 \%$ reduction in the hazard of acute cardiovascular events if every woman had been adherent to statins as compared to them being non-adherent. The result was robust against different specifications of statistical models applied. In our study, measured time-dependent confounding was obviously not strong because MSMs accounting for it produced effect estimates which were of the same magnitude as the estimates from conventional analyses after adjusting only for baseline confounders. Measured baseline confounding was not particularly strong either as the crude HR was very close to the adjusted HRs.

Earlier studies on the relationship between statin adherence and CVD in primary prevention populations have attempted to account for time-dependent confounding by occurrence of other forms of $\mathrm{CVD}^{2-5}$ or changes in the intensity of statin therapy ${ }^{4}{ }^{6}$ during the follow-up (table 4). They have measured adherence and time-dependent confounders at the same time point, and potentially induced bias in the causal analysis. Adjustment for intermediate variables along the causal pathway in addition to different definitions for adherence, outcomes and populations in primary prevention (table 4) may be reasons for the differences in the estimated reductions in the event incidence when compared to our results. ${ }^{10}$ In our study, addition of time-dependent confounders measured simultaneously with adherence (ie, intermediate variables) to the adherence models for MSM produced a slightly stronger association between adherence and acute cardiovascular events (HR: $0.74,95 \%$ CI 0.61 to 0.89 ) than our original MSM (HR: $0.78,95 \%$ CI 0.64 to 0.93 ). In the presence of unmeasured predictors that are causes both for an intermediate variable and the outcome, conditioning on the intermediate variable may open a non-causal path between adherence and the outcome and may, thereby, create an additional association. ${ }^{10} 38$ Thus, due to adjustment for intermediate variables, the apparent effect may be weaker or stronger than the true effect.

In the comparison between individuals who were slightly adherent with the extremely non-adherent, we observed a potential but non-significant effect (HR: $0.85,95 \%$ CI 0.62 to 1.16 ) on the hazard of acute cardiovascular events. This observed effect for statins is reasonable in comparison with the results emerging from primary prevention trials (risk ratios 0.67 for non-fatal myocardial infarction, and 0.69 for non-fatal stroke over a maximum of 5.3 years of follow-up ${ }^{39}$ ) as the average adherence level among those with at least one refill was most likely lower than adherence levels in these controlled trials.

Our study has several strengths. First, we expanded on the previous studies by accounting for time-dependent confounding affected by previous adherence in addition to the time dependence of adherence. ${ }^{40}$ Specifically, we used lagged time-dependent confounders in the IPTW construction to ensure that we had a proper time sequence. Adherence was measured as PDC in yearly periods and dichotomised using $80 \%$ as a cut-off value. Although the method improved measurement of adherence compared to the earlier studies, where adherence was typically measured as a fixed value throughout the follow-up, ${ }^{2-7}$ it produced rough estimates. Recently, Bijlsma et $a t^{41}$ extended the PDC method to quantify adherence in the time intervals between consecutive prescriptions, and the method was shown to produce more precise estimates compared with a fixed-time PDC measure. Second, as both medical procedures related to CHD and death from any cause can be regarded as a competing risk for acute cardiovascular events, we formed a new composite end point for the sensitivity analysis to account for the potential selection bias ${ }^{35}$ and observed that these competing risks did not contribute appreciably to the bias. Finally, we used low-energy fractures as a negative control outcome, and observed a $10 \%$, non-significant reduction in the hazard of fractures suggesting that part of the observed effect of statin adherence on acute cardiovascular events may be due to the healthy-adherer effect. It is noteworthy, however, that unmeasured confounding by body mass index may have changed the HRs for fractures and CVD events in opposite directions: being overweight and obesity seem to improve statin adherence, ${ }^{42}$ and are known to lower fracture risk. ${ }^{43}$ However, these may increase the risk of CHD. ${ }^{44}$ Other approaches to adjust effect estimates for unmeasured confounding include, for example, integration of validation data ${ }^{45}$ and instrumental variable analysis. ${ }^{46}$ In our recent study, ${ }^{8}$ healthy-adherer effect was examined using propensity score calibration with an external validation study to adjust for selected lifestyle factors (body mass index, smoking, alcohol use, physical activity) and self-reported health. However, no major effect on the effect estimate was found. Finally, conducting a randomised controlled trial would guarantee exchangeability between the groups at baseline, but the design is not feasible for examining the effects of medication adherence. $^{47}$

Yet we may have introduced selection bias when conditioning on survival plus remaining non-institutionalised and free of outcomes during the first adherence ascertainment year. ${ }^{48}$ There may be factors such as poor health status that lead to both early exclusion and are independent risk factors for acute cardiovascular events. Statin therapy and thus adherence to this therapy, however, is not likely to have appreciably affected the CVD event risk or survival during the first year of use. ${ }^{20-24}$ Furthermore, we did not attempt to adjust for potentially differential loss to follow-up due to long-term institutionalisation because the proportion of patients institutionalised was low $(0.3 \%)$. Our adherence measure assumes that PDC corresponds to the proportion of days of medication use, but we could not confirm whether dispensed statins were actually consumed. Acute cardiovascular events were captured from 


\begin{tabular}{|c|c|c|c|c|c|c|c|}
\hline $\begin{array}{l}\text { Country, design, } \\
\text { study population }\end{array}$ & $\begin{array}{l}\text { Max follow-up } \\
\text { (years) }\end{array}$ & $\begin{array}{l}\text { Exposure } \\
\text { definition }\end{array}$ & $\begin{array}{l}\text { Exposure } \\
\text { classification }\end{array}$ & $\begin{array}{l}\text { Time-dependent } \\
\text { confounders }\end{array}$ & Outcome & $\begin{array}{l}\text { Crude effect } \\
\text { estimate }(95 \% \mathrm{Cl})\end{array}$ & $\begin{array}{l}\text { Adjusted effect } \\
\text { estimate }(95 \% \mathrm{Cl})\end{array}$ \\
\hline $\begin{array}{l}\text { Canada }^{2} \\
(\mathrm{n}=12180), \text { nested } \\
\text { case-control, } 50- \\
64 \text { years, } 65 \% \text { ? }\end{array}$ & 3.5 & $\begin{array}{l}\text { PDC from statin } \\
\text { initiation to time } \\
\text { of outcome }\end{array}$ & $\begin{array}{l}\geq 90 \% \\
<90 \%\end{array}$ & $\begin{array}{l}\text { Cardiac comorbidities } \\
\text { measured during the } \\
\text { follow-up }\end{array}$ & $\begin{array}{l}\text { Non-fatal CHD after } \\
\text { 1st year of follow-up }\end{array}$ & $\begin{array}{l}\text { RR } 0.84 \text { (not reported) } \\
1.00\end{array}$ & $\begin{array}{l}\text { RR } 0.81 \text { (0.67 to } 0.97) \\
1.00\end{array}$ \\
\hline $\begin{array}{l}\text { Canada }^{3} \\
(\mathrm{n}=147601) \\
\text { nested case- } \\
\text { control, } 45- \\
85 \text { years, } 63 \% \text { \& }\end{array}$ & 6.5 & $\begin{array}{l}\text { MPR from } \\
\text { statin initiation } \\
\text { to time of } \\
\text { outcome }\end{array}$ & $\begin{array}{l}\geq 80 \% \\
60-79 \% \\
40-59 \% \\
20-39 \% \\
<20 \%\end{array}$ & $\begin{array}{l}\text { Cardiac and non-cardiac } \\
\text { comorbidities and } \\
\text { medication use measured } \\
\text { during the follow-up }\end{array}$ & $\begin{array}{l}\text { Non-fatal CHD or } \\
\text { all-cause death after } \\
\text { 1st year of follow-up }\end{array}$ & $\begin{array}{l}\text { RR } 0.90 \text { (0.85 to } 0.96) \\
0.92(0.85 \text { to } 1.00) \\
0.94(0.86 \text { to } 1.02) \\
0.95(0.87 \text { to } 1.04) \\
1.00\end{array}$ & $\begin{array}{l}\text { RR } 0.82 \text { (0.77 to } 0.87) \\
0.85(0.78 \text { to } 0.92) \\
0.87(0.80 \text { to } 1.00) \\
0.91(0.84 \text { to } 1.01) \\
1.00\end{array}$ \\
\hline $\begin{array}{l}\text { Canada }^{4} \\
(\mathrm{n}=41140), \text { nested } \\
\text { case-control, } 45- \\
85 \text { years, } 63 \% \text { ᄋ }\end{array}$ & 6.5 & $\begin{array}{l}\text { MPR from } \\
\text { statin initiation } \\
\text { to time of } \\
\text { outcome }\end{array}$ & $\begin{array}{l}\geq 80 \% \\
60-79 \% \\
40-59 \% \\
20-39 \% \\
<20 \%\end{array}$ & $\begin{array}{l}\text { Cardiac and non-cardiac } \\
\text { comorbidities measured } \\
\text { during the follow-up }\end{array}$ & $\begin{array}{l}\text { Non-fatal } \\
\text { cerebrovascular } \\
\text { disease after 1st year } \\
\text { of follow-up }\end{array}$ & $\begin{array}{l}\text { RR } 0.83(0.74 \text { to } 0.93) \\
0.93(0.80 \text { to } 1,07) \\
0.90(0.76 \text { to } 1.06) \\
1.01(0.86 \text { to } 1.19) \\
1.00\end{array}$ & $\begin{array}{l}\text { RR } 0.74(0.65 \text { to } 0.84) \\
0.82(0.71 \text { to } 0.96) \\
0.83(0.70 \text { to } 0.98) \\
0.97(0.83 \text { to } 1.15) \\
1.00\end{array}$ \\
\hline $\begin{array}{l}\text { Italy }{ }^{5}(n=90832) \\
\text { cohort, } \geq 18 \text { years } \\
\text { (mean } 62 \text { years), } \\
59 \% \text { ᄋ }\end{array}$ & 6 & $\begin{array}{l}\text { PDC from statin } \\
\text { initiation to time } \\
\text { of each } \\
\text { outcome }\end{array}$ & $\begin{array}{l}>75 \% \\
51-75 \% \\
26-50 \% \\
\leq 25 \%\end{array}$ & $\begin{array}{l}\text { Concomitant cardiac } \\
\text { medication use, and } \\
\text { switching of statins } \\
\text { measured during the } \\
\text { follow-up }\end{array}$ & $\begin{array}{l}\text { Non-fatal CHD after } \\
1 \text { st year of follow-up }\end{array}$ & $\begin{array}{l}\text { HR } 0.97(0.85 \text { to } 1.12) \\
0.90(0.79 \text { to } 1.04) \\
0.86(0.75 \text { to } 0.99) \\
1.00\end{array}$ & $\begin{array}{l}\text { HR } 0.81(0.71 \text { to } 0.94) \\
0.82(0.71 \text { to } 0.95) \\
0.85(0.72 \text { to } 0.98) \\
1.00\end{array}$ \\
\hline $\begin{array}{l}\text { Israel }^{6}(n=171535) \\
\text { cohort, } 45- \\
75 \text { years, } 58 \% \text { ᄋ }\end{array}$ & 12 & $\begin{array}{l}\text { MPR from } \\
\text { statin initiation } \\
\text { to time of } \\
\text { outcome }\end{array}$ & $\begin{array}{l}\geq 80 \% \\
60-79 \% \\
40-59 \% \\
20-39 \% \\
<20 \%\end{array}$ & $\begin{array}{l}\text { Efficacy of statin therapy } \\
\text { measured during the } \\
\text { follow-up }\end{array}$ & $\begin{array}{l}\text { Non-fatal CHD or } \\
\text { stroke after 1st year } \\
\text { of follow-up }\end{array}$ & Not reported & $\begin{array}{l}\text { HR } 0.64(0.60 \text { to } 0.67) \\
0.63(0.59 \text { to } 0.67) \\
0.71(0.67 \text { to } 0.75) \\
0.90(0.85 \text { to } 0.96) \\
1.00\end{array}$ \\
\hline
\end{tabular}

Table 4 Population-based studies on the effect of statin adherence on cardiovascular morbidity in primary prevention of cardiovascular disease that have adjusted fo time-dependent confounding 
primary discharge diagnoses in the Finnish Care Register. Validation studies of the register have reported a positive predictive value of $80 \%$ for ischaemic stroke among women aged 25 years and older during the years 1993-1998, and that of $69 \%$ for ACS among women aged 35-74 years during 1998-2002 when compared with the Finnish population-based stroke and myocardial infarction registers. ${ }^{49}$ The temporal distance between the observed adherence and outcomes of interest was between 1 and 365 days. It is possible that the risk of outcome has been affected by changes in the adherence level during the outcome assessment period. Furthermore, our study population consisted of women who initiated statin use in the early 2000s. Subsequently, there has been a shift towards more intensive statin therapy leading to potentially larger relative benefits associated with adherence. ${ }^{28}$ Lastly, MSM assumes no unmeasured confounding, but we had no data on some important confounders, such as cholesterol level, blood pressure, smoking or family history of CVD. However, we were able to adjust for presence of the most severe forms of hypertension and dyslipidemia leading to hospitalisation or entitlement to special reimbursement, which may have partly controlled for confounding by cholesterol and blood pressure levels.

\section{CONCLUSIONS}

This paper supports the earlier results of the beneficial effect of sufficient adherence to statin therapy for patients in primary prevention of CVD. We also showed that accounting for the confounding factors on the causal pathway correctly did not appreciably change this result, presumably because time-dependent confounding was not strong.

\section{Author affiliations \\ ${ }^{1}$ Department of Pharmacology, Drug Development and Therapeutics, University of Turku, Turku, Finland \\ ${ }^{2}$ Drug Research Doctoral Programme, University of Turku, Turku, Finland \\ ${ }^{3}$ Unit of Primary Health Care, Hospital District of Helsinki and Uusimaa, Helsinki, Finland \\ ${ }^{4}$ The Center of Statistics, University of Turku, Turku, Finland \\ ${ }^{5}$ Division of Pharmaceutical Outcomes and Policy, Eshelman School of Pharmacy, University of North Carolina, Chapel Hill, North Carolina, USA \\ ${ }^{6}$ Heart Center, Kuopio University Hospital, Kuopio, Finland \\ ${ }^{7}$ School of Medicine, University of Eastern Finland, Kuopio, Finland \\ ${ }^{8}$ Department of Clinical Pharmacology, Tykslab, Turku University Hospital, Turku, Finland}

Contributors PL participated in conception and design of the study, performed and was responsible for statistical analyses, participated in interpretation of data, and wrote the first version of the manuscript. AH-S participated in the conception and design of the study, and in interpretation of the data, drafted the article and revised it critically for important intellectual content. ME supervised the statistical analyses, participated in interpretation of data and revised the article critically for important intellectual content. GF participated in analyses and interpretation of data, reviewed the article and revised it critically for important intellectual content. JH participated in interpretation of data and revised the article critically for important intellectual content. RH participated in conception and design of the study, and revised the article critically for important intellectual content. MJK participated in conception and design of the study, and was responsible for the acquisition of data and for statistical analyses, participated in interpretation of data, and drafted the article and revised it critically for important intellectual content. The final approval of the version to be published was approved by all the authors.

Funding The study was funded by the Academy of Finland (http://www.aka.fi, decision number 138255) and the Social Insurance Institution of Finland (decision number 10/26/2007). The Academy of Finland and the Social Insurance Institution had no role in the design, analyses, interpretation of data, writing of the report, or in the decision to submit the manuscript.

Competing interests AH-S, MJK and RH have been funded by grants from the Social Insurance Institution and the Academy of Finland. RH is a member of the Advisory Board for Social and Medical Affairs of the Social Insurance Institution of Finland. JH has received research grants from the Finnish Foundation for Cardiovascular Research and the European Union Seventh Framework Programme. He has given lectures for Cardiome, St Jude Medical and Biotronic, and has been a member of the advisory boards for Astra Zeneca, Amgen, and Bayer. GF receives research funding from the US National Institute of Aging, Patient Centered Outcomes Research Institute, and Agency for Healthcare Research and Quality.

Provenance and peer review Not commissioned; externally peer reviewed.

Data sharing statement No additional data are available.

Open Access This is an Open Access article distributed in accordance with the Creative Commons Attribution Non Commercial (CC BY-NC 4.0) license, which permits others to distribute, remix, adapt, build upon this work noncommercially, and license their derivative works on different terms, provided the original work is properly cited and the use is non-commercial. See: http:// creativecommons.org/licenses/by-nc/4.0/

\section{REFERENCES}

1. Osterberg L, Blaschke T. Adherence to medication. $N$ Engl J Med 2005;353:487-97.

2. Bouchard $\mathrm{MH}$, Dragomir A, Blais J, et al. Impact of adherence to statins on coronary artery disease in primary prevention. $\mathrm{Br} \mathrm{J}$ Clin Pharmacol 2007;63:698-708.

3. Perreault S, Dragomir A, Blais L, et al. Impact of better adherence to statin agents in the primary prevention of coronary artery disease. Eur J Clin Pharmacol 2009;65:1013-24.

4. Perreault S, Ellia L, Dragomir A, et al. Effect of statin adherence on cerebrovascular disease in primary prevention. $\mathrm{Am} \mathrm{J} \mathrm{Med}$ 2009;122:647-55.

5. Corrao G, Conti V, Merlino L, et al. Results of a retrospective database analysis of adherence to statin therapy and risk of nonfatal ischemic heart disease in daily clinical practice in Italy. Clin Ther 2010;32:300-10.

6. Shalev V, Goldshtein I, Porath A, et al. Continuation of statin therapy and primary prevention of nonfatal cardiovascular events. Am J Cardiol 2012;110:1779-86.

7. Slejko JF, Ho PM, Anderson HD, et al. Adherence to statins in primary prevention: yearly adherence changes and outcomes. J Manag Care Pharm 2014;20:51-7.

8. Rannanheimo PK, Tiittanen P, Hartikainen J, et al. Impact of statin adherence on cardiovascular morbidity and all-cause mortality in the primary prevention of cardiovascular disease: a population-based cohort study in Finland. Value Health 2015;18:896-905.

9. Korhonen MJ, Helin-Salmivaara A, Huupponen R. Dynamics of long-term statin therapy. Eur J Clin Pharmacol 2011;67:925-31.

10. Robins JM, Hernán MA, Brumback B. Marginal structural models and causal inference in epidemiology. Epidemiology 2000;11:550-60.

11. Daniel RM, Cousens SN, De Stavola BL, et al. Methods for dealing with time-dependent confounding. Statist Med 2013;32:1584-618.

12. Brookhart MA, Patrick AR, Dormuth $C$, et al. Adherence to lipid-lowering therapy and the use of preventive health services: an investigation of the healthy user effect. Am J Epidemiol 2007;166:348-54.

13. Dormuth CR, Patrick AR, Shrank WH, et al. Statin adherence and risk of accidents: a cautionary tale. Circulation 2009;119:2051-7.

14. Patrick AR, Shrank WH, Glynn RJ, et al. The association between statin use and outcomes potentially attributable to an unhealthy lifestyle in older adults. Value Health 2011;14:513-20.

15. Dusetzina SB, Brookhart MA, Maciejewski ML. Control outcomes and exposures for improving internal validity of nonrandomized studies. Health Serv Res 2015;50:1432-51. 
16. Robins JM. Causal models for estimating the effects of weight gain on mortality. Int J Obes (Lond) 2008;32:S15-41.

17. Hernán MA, Brumback $B$, Robins JM. Marginal structural models to estimate the causal effect of zidovudine on the survival of HIV-positive men. Epidemiology 2000;11:561-70.

18. About the ATC/DDD system. WHO. http://www.whocc.no/atcddd/ (accessed Jan 2016)

19. Andrade SE, Kahler KH, Frech F, et al. Methods for evaluation of medication adherence and persistence using automated databases. Pharmacoepidemiol Drug Saf 2006;15:565-74.

20. Colhoun HM, Betteridge DJ, Durrington PN, et al. Primary prevention of cardiovascular disease with atorvastatin in type 2 diabetes in the Collaborative Atorvastatin Diabetes Study (CARDS): multicentre randomised placebo-controlled trial. Lancet 2004;364:685-96.

21. Mizuno K, Nakaya N, Ohashi $\mathrm{Y}$, et al. Usefulness of pravastatin in primary prevention of cardiovascular events in women. Analysis of the Management of Elevated Cholesterol in Primary Prevention Group of Adult Japanese (MEGA Study). Circulation 2008;117:494-502.

22. Sever PS, Dahlöf B, Poulter NR, et al. Prevention of coronary and stroke events with atorvastatin in hypertensive patients who have average or lower-than-average cholesterol concentrations, in the Anglo-Scandinavian Cardiac Outcomes Trial-Lipid Lowering Arm (ASCOT-LLA): a multicenter randomized controlled trial. Lancet 2003;361:1149-58.

23. Downs JR, Clearfield M, Weis $\mathrm{S}$, et al. Primary prevention of acute coronary events with lovastatin in men and women with average cholesterol levels. Results of AFCAPS/TexCAPS. JAMA 1998;279:1615-22.

24. Bukkapatnam RN, Gabler NB, Lewis WR. Statins for primary prevention of cardiovascular mortality in women: a systematic review and meta-analysis. Prev Cardiol 2010;13:84-90.

25. Leslie SR, Gwadry-Sridhar F, Thiebaud P, et al. Calculating medication compliance, adherence and persistence in administrative pharmacy claims databases. Pharm Program 2008;1:13-19.

26. Romppainen T, Rikala M, Aarnio E, et al. Measurement of statin exposure in the absence of information on prescribed doses. Eur $J$ Clin Pharmacol 2014:70:1275-6.

27. Karve S, Cleves MA, Helm M, et al. Good and poor adherence: optimal cut-point for adherence measures using administrative claims data. Curr Med Res Opin 2009;25:2303-10.

28. Chowdhury R, Khan H, Heydon E, et al. Adherence to cardiovascular therapy: a meta-analysis of prevalence and clinical consequences. Eur Heart J 2013;34:2940-8.

29. Lefebvre G, Delaney JAC, Platt RW. Impact of mis-specification of the treatment model on estimates from a marginal structural model. Statist Med 2008;27:3629-42.

30. Brookhart MA, Schneeweiss S, Rothman KJ, et al. Variable selection for propensity score models. Am J Epidemiol 2006;163:1149-56.

31. Stone NJ, Robinson J, Lichtenstein $\mathrm{AH}$, et al. ACC/AHA guideline on the treatment of blood cholesterol to reduce atherosclerotic cardiovascular risk in adults: a report of the American College of Cardiology/American Heart Association Task Force on Practice Guidelines. Circulation 2013:129:S1-45.
32. Quan $\mathrm{H}$, Sundararajan $\mathrm{V}$, Halfon $\mathrm{P}$, et al. Coding algorithms for defining comorbidities in ICD-9-CM and ICD-10 administrative data. Med Care 2005;43:1130-9.

33. Kaufman J. Marginalia: comparing adjusted effect measures. Epidemiology 2010;21:490-3.

34. Cole SR, Hernán MA. Constructing inverse probability weights for marginal structural models. Am J Epidemiol 2008;168:656-64.

35. Austin PC. Goodness-of-fit diagnostics for the propensity score model when estimating treatment effects using covariate adjustment with the propensity score. Pharmacoepidemiol Drug Saf 2008; 17:1202-17.

36. Hernán MA, Schisterman EF, Hernández-Díaz S. Invited commentary: composite outcomes as an attempt to escape from selection bias and related paradoxes. Am J Epidemiol 2014;179:368-70.

37. Peña JM, Aspberg S, MacFadyen J, et al. Statin therapy and risk of fracture. Results from the JUPITER randomized clinical trial. JAMA Intern Med 2015;175:171-7.

38. Hernán MA, Hernández-Díaz S, Robins JM. A structural approach to selection bias. Epidemiology 2004;15:615-25.

39. Taylor F, Huffman MD, Macedo AF, et al. Statins for the primary prevention of cardiovascular disease. Cochrane Database Syst Rev 2013;1:CD004816.

40. Parienti JJ. The art of modeling adherence: shades or shapes? Pharmacoepidemiol Drug Saf 2015;24:1114-16.

41. Bijlsma MJ, Janssen F, Hak E. Estimating time-varying drug adherence using electronic records: extending the proportion of days covered (PDC) method. Pharmacoepidemiol Drug Saf 2016;25:325-32.

42. Halava H, Korhonen MJ, Huupponen R, et al. Lifestyle factors as predictors of nonadherence to statin therapy among patients with and without cardiovascular comorbidities. CMAJ 2014;186:E449-56.

43. Johansson $\mathrm{H}$, Kanis JA, Odén $\mathrm{A}$, et al. A meta-analysis of the association of fracture risk and body mass index in women. $J$ Bone Miner Res 2014;29:223-33.

44. Canoy D, Cairns BJ, Balkwill A, et al. Body mass index and incident coronary heart disease in women: a population-based prospective study. BMC Med 2013;11:87-95.

45. Stürmer T, Glynn RJ, Rothman KJ, et al. Adjustments for unmeasured confounders in pharmacoepidemiologic database studies using external information. Med Care 2007;45:S158-65.

46. Greenland S. An introduction to instrumental variables for epidemiology. Int J Epidemiol 2000;29:722-9.

47. Choudhry NK, Glynn RJ, Avorn J, et al. Untangling the relationship between medication adherence and post-myocardial infarction outcomes: medication adherence and clinical outcomes. Am Heart $J$ 2014;167:51-8.

48. Cole SR, Platt RW, Schisterman EF, et al. Illustrating bias due to conditioning on a collider. Int J Epidemiol 2010;39:417-20.

49. Tolonen H, Salomaa V, Torppa J, et al. The validation of the Finnish Hospital Discharge Register and Causes of Death Register data on stroke diagnoses. Eur J Cardiovasc Prev Rehabil 2007;14:380-5.

50. Pajunen $\mathrm{P}$, Koukkunen $\mathrm{H}$, Ketonen $\mathrm{M}$, et al. The validity of the Finnish Hospital Discharge Register and Causes of Death Register data on coronary heart disease. Eur J Cardiovasc Prev Rehabil 2005;12:132-7. 